\title{
High-dose Chemotherapy Response in Adults with Relapsed/Refractory Small Round Cell Tumours
}

\author{
Musa Baris Aykan, Ismail Erturk, Ramazan Acar, Gül Sema Yildiran, Birol Yildiz and Nuri Karadurmus \\ Department of Medical Oncology, University of Health Sciences, Gulhane School of Medicine, Ankara, Turkey
}

\begin{abstract}
Objective: To demonstrate the treatment responses, survival analysis, and treatment-related mortality characteristics of high-dose chemotherapy (HDC) in patients with relapsed/refractory Ewing sarcoma (ES), osteosarcoma, rhabdomyosarcoma (RMS) and medulloblastoma (MB).

Study Design: Observational study.

Place and Duration of Study: Department of Medical Oncology, University of Health Sciences, Gulhane School of Medicine, from January 2016 and April 2020.

Methodology: Clinical features and follow-up data of relapsed/refractory ES, osteosarcoma, RMS and MB patients treated with HDC were recorded from the patients' registration database of the hospital. Patients $<16$ years and those whose medical records were not available were excluded. Progression-free survival (PFS), one-year overall survival (OS) rates and treatment-related mortality (TRM) after the HDC were determined. Ifosfamide, carboplatin and etoposide (HD-ICE) were used as the HDC protocol in all patients.

Results: Thirty-seven adult patients were included. PFS was determined as $2.70 \pm 0.97$ months, $11.57 \pm 3.63$ months, 3.47 \pm 0.44 months and $2.96 \pm 0.91$ months, for ES, MB, RMS and osteosarcoma, respectively. One-year OS rate was $44.8 \pm$ $14.8 \%$ for ES; $75 \pm 15.8 \%$ for MB. In ES, PFS was found to be better in males than females ( $p=0.025)$. No patient died during HD-ICE. Mortality was observed most frequently in the RMS in the first 100 days (25\%).

Conclusion: HD-ICE treatment may be an option in relapsed/refractory small round cell tumours (SRCT). Significant progression-free survival can be achieved in patients who received at least two lines of treatment, with acceptable treatment-related mortality.
\end{abstract}

Key Words: Small round cell tumours, Ewing sarcoma, Osteosarcoma, Rhabdomyosarcoma, Medulloblastoma, High-dose chemotherapy, Autologous stem cell transplantation.

How to cite this article: Aykan MB, Erturk I, Acar R, Yildiran GS, Yildiz B, Karadurmus N. High-dose Chemotherapy Response in Adults with Relapsed/Refractory Small Round Cell Tumours. J Coll Physicians Surg Pak 2022; 32(01):51-56.

\section{INTRODUCTION}

Small round cell tumours (SRCT) is the term used to describe malignant neoplasms that are highly aggressive. These tumour family members include Ewing sarcoma (ES), osteosarcoma, rhabdomyosarcoma (RMS), medulloblastoma (MB), as well as other tumours. ${ }^{1} \mathrm{ES}$ and osteosarcoma are the most common primary bone tumours in young adults ( $<21$ years) ${ }^{2,3}$ About $30-40 \%$ of ES patients, who achieve remission with first-line treatment, relapse occurs later on. ${ }^{4}$

Correspondence to: Dr. Musa Baris Aykan, Department of Medical Oncology, University of Health Sciences, Gulhane School of Medicine, Etlik, Ankara, Turkey

E-mail: musabarisaykan@gmail.com

Received: July 23, 2021; Revised: October 15, 2021;

Accepted: November 15, 2021

DOI: https://doi.org/10.29271/jcpsp.2022.01.51
In primary metastatic ES and recurrent/refractory osteosarcoma or metastatic osteosarcoma, the overall survival (OS) rate is around $20-40 \%{ }^{5,6}$

RMS is in the most common soft tissue tumours of childhood. ${ }^{7.8}$ In the case of metastasis and other poor prognostic factors (e.g. unfavourable histologies like alveolar RMS), the cure is achieved only about $25 \%{ }^{9}$

Adult MB is exceedingly rare and accounts for $<1 \%$ of intracranial tumours. Five-year progression-free survival (PFS) rates are reported to be $40-45 \%$. The recurrence rate in adult MB is between $50-60 \%$. The median survival after recurrence is around 15 months. ${ }^{10,11}$

The rationale for using high-dose chemotherapy (HDC) with autologous stem cell transplantation (ASCT) rescue is based on the fact that SRCTs are chemosensitive. However, HDC eventually causes dose-limiting hematopoietic toxicity. The tolerable dose of chemotherapy is increased through ASCT rescue. Thus, the most severe side effect of dose intensification can be eliminated in a short time. ${ }^{12}$ 
Table I: The demographic and disease-related characteristics of the patients.

\begin{tabular}{|c|c|c|c|c|}
\hline Features & $\begin{array}{l}\text { Ewing Sarcoma } \\
(n=20)\end{array}$ & $\begin{array}{l}\text { Medulloblastoma } \\
(n=10)\end{array}$ & $\begin{array}{l}\text { Rhabdomyosarcoma } \\
(n=4)\end{array}$ & $\begin{array}{l}\text { Osteosarcoma } \\
(n=3)\end{array}$ \\
\hline Age (mean \pm SD) & $26.85 \pm 8.57$ & $29.40 \pm 8.98$ & $25.25 \pm 2.5$ & $21 \pm 3$ \\
\hline Male Gender, n (\%) & $14(70 \%)$ & $4(40 \%)$ & $3(75 \%)$ & $3(100 \%)$ \\
\hline \multicolumn{5}{|l|}{ Primary tumour location. $\mathrm{n}(\%)$} \\
\hline Extremities & $17(85 \%)$ & - & $1(25 \%)$ & $3(100 \%)$ \\
\hline Cerebellum & - & $10(\% 100)$ & - & - \\
\hline \multicolumn{5}{|l|}{ Stage at the time of diagnosis, $\mathrm{n}(\%)$} \\
\hline Stage 3 & $5(25 \%)$ & - & $1(25 \%)$ & $1(33.3 \%)$ \\
\hline Stage 4 & $9(45 \%)$ & $10(100 \%)$ & $3(75 \%)$ & $2(66.6 \%)$ \\
\hline Lung metastases, $\mathrm{n}(\%)$ & $7(35 \%)$ & - & $1(25 \%)$ & $1(33.3 \%)$ \\
\hline \multicolumn{5}{|l|}{ Radiotherapy, n (\%) } \\
\hline Adjuvant & $6(30 \%)$ & $10(100 \%)$ & $2(50 \%)$ & - \\
\hline Palliative & $5(25 \%)$ & - & $2(50 \%)$ & $1(33.3 \%)$ \\
\hline Neoadjuvant Chemotherapy, $\mathrm{n}(\%)$ & $7(35 \%)$ & - & $1(25 \%)$ & $3(100 \%)$ \\
\hline Surgery, $\mathrm{n}(\%)$ & $10(50 \%)$ & $10(100 \%)$ & $1(25 \%)$ & $3(100 \%)$ \\
\hline Adjuvant Chemotherapy, n (\%) & $19(95 \%)$ & $7(70 \%)$ & $4(100 \%)$ & $3(100 \%)$ \\
\hline \multicolumn{5}{|l|}{ Time to relapse, $\mathrm{n}(\%)$} \\
\hline$<2$ years & $13(65 \%)$ & $3(30 \%)$ & $3(75 \%)$ & $1(33.3 \%)$ \\
\hline \multicolumn{5}{|l|}{ Extrapulmonary relapse, $\mathrm{n}(\%)$} \\
\hline Yes & $11(55 \%)$ & - & $1(25 \%)$ & $1(33.3 \%)$ \\
\hline \multicolumn{5}{|l|}{ Number of lines before HD-ICE treatment, $n(\%)$} \\
\hline 2 lines & $17(85 \%)$ & $6(60 \%)$ & $2(50 \%)$ & $3(100 \%)$ \\
\hline Amount of stem cells given $10^{6} / \mathrm{L}$ (mean \pm SD) & $3.89 \pm 1.82$ & $4.38 \pm 1.53$ & $3.8 \pm 2.08$ & $5.66 \pm 2.30$ \\
\hline Engraftment Time (days) (mean \pm SD) & $11.75 \pm 1.97$ & $12.60 \pm 2.91$ & $9.5 \pm 0.57$ & $10.33 \pm 1.52$ \\
\hline
\end{tabular}

Table II: The PFS, OS and follow-up characteristics of the patients and characteristics of the patients' toxicity profiles during AHSCT.

\begin{tabular}{|c|c|c|c|c|}
\hline Features & $\begin{array}{l}\text { Ewing Sarcoma } \\
(n=20)\end{array}$ & $\begin{array}{l}\text { Medulloblastoma } \\
(n=10)\end{array}$ & $\begin{array}{l}\text { Rhabdomyosarcoma } \\
(\mathrm{n}=4)\end{array}$ & $\begin{array}{l}\text { Osteosarcoma } \\
(n=3)\end{array}$ \\
\hline $\begin{array}{l}\text { PFS after first-line treatment } \\
\text { (months) (mean } \pm \text { SE) }\end{array}$ & $15.02 \pm 0.83$ & $44.98 \pm 13.79$ & $10.45 \pm 5.0$ & $19.46 \pm 7.40$ \\
\hline $\begin{array}{l}\text { PFS after second-line treatment } \\
\text { (months) (mean } \pm \mathrm{SE} \text { ) }\end{array}$ & $10.19 \pm 2.11$ & $3.25 \pm 0.32$ & $2.7 \pm 0.84$ & $7.3 \pm 1.02$ \\
\hline \multicolumn{5}{|c|}{ The response of the patients after ASCT $n(\%)$} \\
\hline Complete response & $7(35 \%)$ & $6(60 \%)$ & $1(25 \%)$ & - \\
\hline Partial response & $2(10 \%)$ & $2(20 \%)$ & - & - \\
\hline Stable response & $2(10 \%)$ & $2(20 \%)$ & $1(25 \%)$ & $1(33.3 \%)$ \\
\hline Progressive disease & $9(45 \%)$ & - & $2(50 \%)$ & $2(66.6 \%)$ \\
\hline $\begin{array}{l}\text { PFS after HD-ICE treatment } \\
\text { (months) (mean } \pm \text { SE) }\end{array}$ & $2.70 \pm 0.97$ & $11.57 \pm 3.63$ & $3.47 \pm 0.44$ & $2.96 \pm 0.91$ \\
\hline \multicolumn{5}{|c|}{ Chemotherapy after ASCT. $\mathrm{n}(\%)$} \\
\hline Yes & $11(55 \%)$ & $1(10 \%)$ & $2(50 \%)$ & $3(100 \%)$ \\
\hline No & $9(55 \%)$ & $9(90 \%)$ & $2(50 \%)$ & - \\
\hline $\begin{array}{l}\text { One-year OS rate after } \\
\text { HD-ICE treatment }(\% \pm \text { SE) }\end{array}$ & $44.8 \pm 14.8$ & $75 \pm 15.8$ & $75 \pm 21.7$ & NA \\
\hline $\begin{array}{l}\text { TRM in the first } 100 \text { days after } \\
\text { HD-ICE, } n(\%)\end{array}$ & $4(20 \%)$ & - & $1(25 \%)$ & - \\
\hline \multicolumn{5}{|l|}{ Febrile neutropenia, n (\%) } \\
\hline Grade 3 & $20(100 \%)$ & $10(100 \%)$ & $4(100 \%)$ & $3(100 \%)$ \\
\hline $\mathrm{Hgb}<10 \mathrm{~g} / \mathrm{dl}, \mathrm{n}(\%)$ & $20(100 \%)$ & $10(100 \%)$ & $4(100 \%)$ & $3(100 \%)$ \\
\hline $\begin{array}{l}\text { Number of ES units transfused } \\
\text { after HD-ICE (mean } \pm \text { SD) }\end{array}$ & $3.55 \pm 2.35$ & $6.00 \pm 2.44$ & $2.25 \pm 0.95$ & $1.66 \pm 0.57$ \\
\hline $\begin{array}{l}\text { After ASCT, } \\
\text { the day when thrombocyte } \\
\left.<20000 / \mathrm{mm}^{3} \text { (mean } \pm \mathrm{SD}\right)\end{array}$ & $4.40 \pm 1.18$ & $3.30 \pm 1.25$ & $4.25 \pm 2.21$ & $4.66 \pm 1.15$ \\
\hline $\begin{array}{l}\text { Number of PAS units transfused } \\
\text { after HD-ICE (mean } \pm \text { SD) }\end{array}$ & $4.50 \pm 1.98$ & $6.20 \pm 3.01$ & $3.50 \pm 1.00$ & $3.66 \pm 2.08$ \\
\hline \multicolumn{5}{|l|}{ Nausea, vomiting, $\mathrm{n}(\%)$} \\
\hline Grade 2 & $5(25 \%)$ & $3(30 \%)$ & $1(25 \%)$ & $2(66.6 \%)$ \\
\hline Grade 3 & $6(30 \%)$ & - & - & $1(33.3 \%)$ \\
\hline \multicolumn{5}{|l|}{ Diarrhoea, n (\%) } \\
\hline Grade 2 & $4(20 \%)$ & $4(40 \%)$ & - & $2(66.6 \%)$ \\
\hline Grade 3 & $4(20 \%)$ & $1(10 \%)$ & - & 2100.0701 \\
\hline
\end{tabular}

The effectiveness of ifosfamide, carboplatin and etoposide (ICE) protocol has been demonstrated in many refractory 
cancers. ${ }^{13,14}$ There is currently no satisfactory randomised prospective study in the literature on the effect of HDC-ASCT on relapsed/refractory SCRTs, particularly when HDC-ASCT is used as a third-line treatment with a single cycle of ICE for the HDC regimen.

In this study, it was aimed to evaluate the survival and progression of patients with relapsed/refractory SCRTs who underwent ASCT and received high dose ICE (HD-ICE).

\section{METHODOLOGY}

This study was designed as a cross-sectional study with a retrospective data collection method. It included 37 patients with relapsed/refractory ES, MB, RMS, and osteosarcoma, older than 16 years, who underwent ASCT with the HD-ICE chemotherapy regimen at Bone Marrow Transplantation Unit, Gulhane Education and Research Hospital between January 2016 and April 2020. Records were assessed for age, gender, primary tumour location, stage at the time of diagnosis, site of metastases on first presentation, lung metastasis situation, previous treatments (radiotherapy, neoadjuvant chemotherapy and adjuvant therapy), relapse time after the first treatment ( $<2$ years or $\geq 2$ years), extrapulmonary relapse situation, number of treatment lines before HD-ICE, data of the ASCT (amount of reinfused stem cells, time of engraftment and transplant-related side effects), PFS and one-year OS rate after HD-ICE and TRM until engraftment, and in the first 100 days and the observed side effects profile.

The inclusion criteria were: being $\geq 16$ years old, patients who received two lines of chemotherapy due to relapsed/refractory ES, MB, RMS or osteosarcoma patients, and those who received HD-ICE protocol in this centre. Those $<16$ year and whose medical records were not available, were excluded.

Patients were divided according to their primary diseases. All patients were given HD-ICE protocol with $12 \mathrm{~g} / \mathrm{m}^{2}$ ifosfamide, $1200 \mathrm{mg} / \mathrm{m}^{2}$ carboplatin, and $1200 \mathrm{mg} / \mathrm{m}^{2}$ etoposide by dividing the total dose into six days. Stem cell reinfusion was performed on the eighth day after two days of rest. For engraftment definition after ASCT, the day like +10 , on which platelet count $>20000 / \mathrm{mm}^{3}$, leukocyte count $>4000 / \mathrm{mm}^{3}$ or neutrophil count $>2000 / \mathrm{mm}^{3}$ occurs first will be accepted as that day. The primary endpoint was to evaluate the patients' PFS, one-year OS rate, and TRM after HD-ICE. Evaluation of treatment-related side effects was also determined as a secondary endpoint.

The local Ethics Committee approved the study protocol (Approval No. 2020/170). All procedures followed the ethical standards of the Turkish medicine and medical devices agency good clinical practices guidelines and the Declaration of Helsinki.

Statistical analyses was performed using SPSS version 22.0 software (SPSS Inc., Chicago, Illinois). Uniformity of contin- uous variables to a normal distribution was examined by using the Kolmogorov-Smirnov test. Normally distributed continuous data were expressed as mean \pm standard deviation (SD). Data that was not normally distributed was expressed as median (interquartile range [IQR]). KaplanMeier survival function analyses and log-rank tests were used to calculate cumulative survival and treatment correlations. A p-value of less than 0.05 was accepted as statistically significant.

\section{RESULTS}

There were 37 patients with male predominance in all groups except MB. While primary tumour localisation was detected as extremities in patients with ES and osteosarcoma ( $85 \%$ and $100 \%$, respectively); in rhabdomyosarcoma, the primary origin was most frequently detected in non-extremity tissues (75\%). The data of the other clinical characteristics, engraftment days and reinfused stem cell amounts of other patients and the demographic and clinical features of the whole group are presented in Table I.

The PFS results observed after the patients' first- and second-line chemotherapy treatments are presented in Table II.

After HD-ICE, overall response rate (ORR), PFS and one-year OS rate are presented in Table II, and Figures 1, 2 and 3. No patient died during HD-ICE. The most common side effect after HD-ICE was determined as myelotoxicity.

The most common non-myelotoxic side effect was nausea and vomiting. Data on other features of the HD-ICE treatment are presented in Table II.

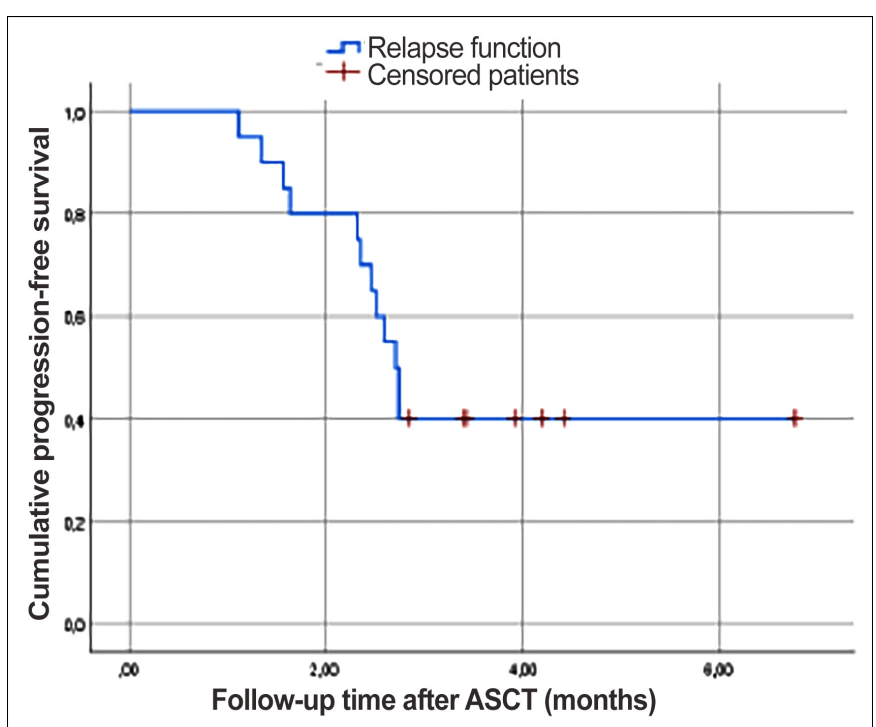

Figure 1: Kaplan-Meier curve of progression-free survival of the patients with Ewing Sarcoma after HD-ICE. 


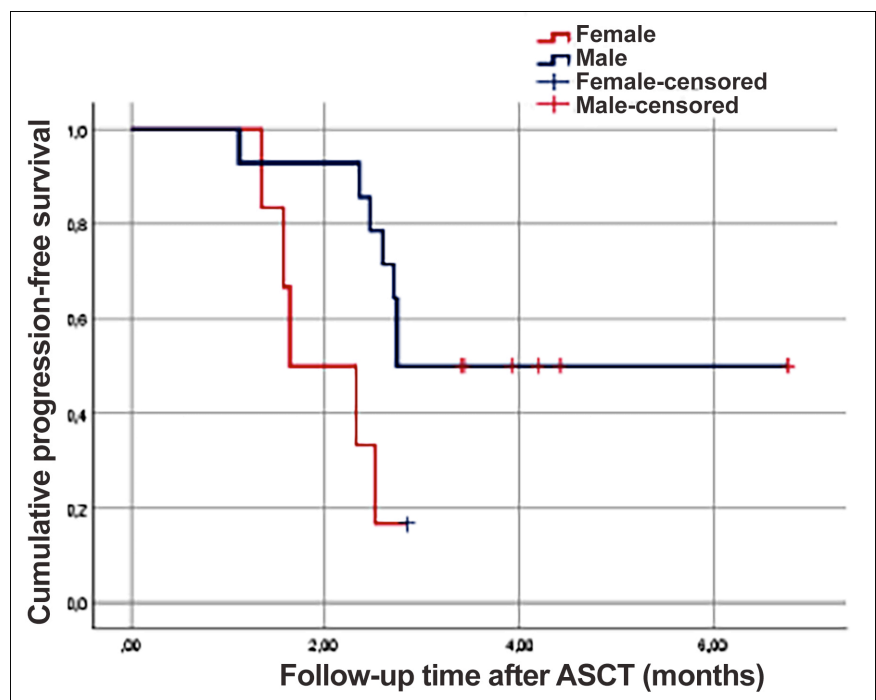

Figure 2: Log-Rank curve of progression-free survival of the patients with Ewing Sarcoma after HD-ICE by gender $(p=0.025)$.

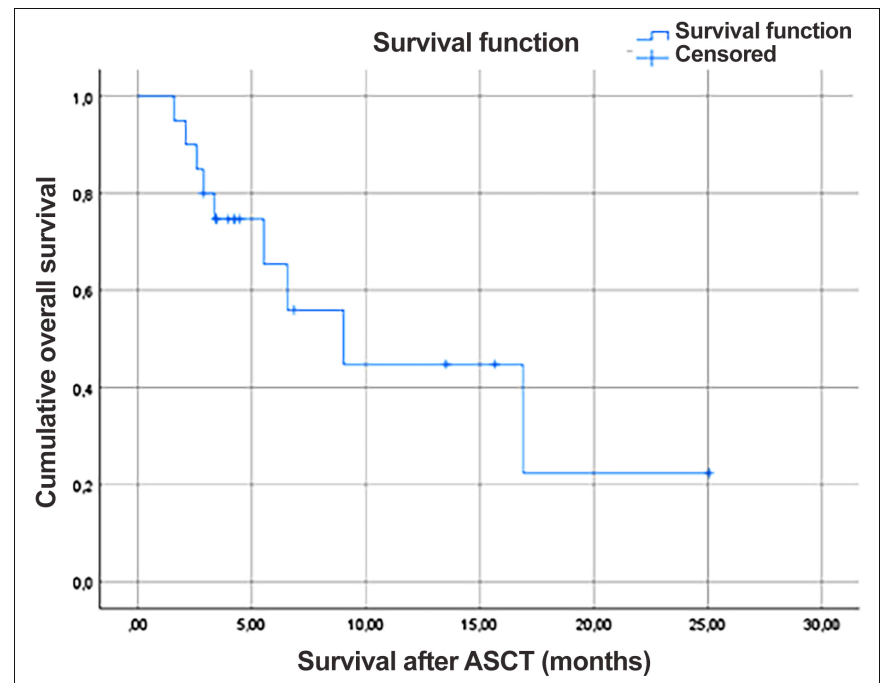

Figure 3: Kaplan-Meier curve of overall survival of the patients with Ewing Sarcoma after HD-ICE.

\section{DISCUSSION}

PFS, one-year-OS rate and TRM results of patients with metastatic SRCTs were determined, who underwent HD-ICE and ASCT. An important possibility that excited the authors is the use of only the ICE protocol as the HDC. The number of publications reporting on this protocol is limited. Patients were primarily evaluated in terms of their stages of diagnosis, metastasis status, treatment modalities, relapse times and PFS duration in the first two lines. After this evaluation, response to HD-ICE, PFS, one-year-OS rate, and TRM were determined. Finally, the toxicity profile was evaluated.

There was complete response (CR) in $35 \%$ of ES, and the duration of PFS in ES was $2.70 \pm 0.97$ months. One-year OS rate after HD-ICE was $44.8 \pm 14.8 \%$. McTierman and colleagues reported a two-year event-free survival (EFS) of $42.5 \%$ with busulfan-based HDC. Patients received HDCASCT after the second relapse or after induction therapy after the first relapse. Approximately half of the patients experienced recurrence after $>2$ years, and $21 \%$ of patients presented with extra-pulmonary relapse. ${ }^{15}$ In this study, $85 \%$ of patients received HD-ICE after the second recurrence, and $65 \%$ of patients had relapsed within two years. Extra-pulmonary relapse was experienced in $55 \%$ of patients. Bacci and colleagues described relapse within two years and extra-pulmonary metastases as bad prognostic factors for OS. ${ }^{16}$ This may be due to the low PFS duration; and OS rate detected were due to poor prognostic factors. Like that by McTiernan and colleagues, in this study, four patients died at similar rates within the first 100 days. Moreover, myelotoxicity was the most common side effect. Death of more patients may be attributed to the higher tumour burden and other poor prognostic factors.

CR was obtained in six patients and partial response (PR) in two patients in the MB group. PFS was $11.57 \pm 3.63$ months. The one-year OS rate was $75 \pm 15.8 \%$. TRM has not been detected. Zia and associates evaluated the effectiveness of HDC-ASCT treatment in six adult relapsed/refractory MB patients. The median duration of response was 13.5 months. Carboplatin, etoposide and cyclophosphamide were used as HDC regimens. ${ }^{17}$ TRM has not been reported. The successful results can be achieved with HD-ICE in adult MB.

Matsubara and colleagues reported HDC-ASCT results in 22 advanced RMS patients. Preparation regimens primarily included etoposide, carboplatin and melphalan. They achieved CR in 14 patients and PR in five patients. The fiveyear OS rate was reported to be $70 \% .{ }^{18}$ The number of studies evaluating only adults is very small, since this tumour is very rare in adults. Additionally, it is known that older age is one of the worst prognoses in RMS patients. In this study, four adult alveolar-type RMS patients were evaluated, and CR was detected in one patient. PFS duration was determined as $3.47 \pm 0.44$ months. Although it is difficult to interpret the present data due to the small number of patients, HD-ICE can be preferred in eligible patients.

Arpaci and colleagues reported HDC-ASCT data in 22 high-grade but non-metastatic primary osteosarcoma patients. All patients were operated after HDC-ASCT and received adjuvant chemotherapy after the operation. Significant tumour necrosis was demonstrated in $>80 \%$ of patients with the neoadjuvant HDC approach. The one-year OS and DFS rates are $100 \%$ and $94 \%$, respectively. They did not report TRM. ${ }^{19}$ Only three adult osteosarcoma patients were examined in this study. Two patients were identified with progressive disease after HD-ICE. PFS was determined as $2.96 \pm 0.91$ months; TRM was not detected. As a result, this treatment modality still constitutes an experimental method for patients who have poor prognostic factors.

This study has several limitations. In retrospective studies, bias may be encountered due to the low ability to keep records. Although SRCT group tumours are rare in adulthood 
and a single-centre experience is presented here, evaluation of OS, PFS and TRM results may be affected by the small number of patients. Retrospective cross-sectional design is the method of this study. Therefore, the results cannot be assumed to be causal.

\section{CONCLUSION}

HD-ICE in SRCT is acceptable due to low TRM and manageable side effects. However, given the results of the study endpoints, this approach is still an experimental treatment modality.

\section{ETHICAL APPROVAL:}

This study was approved by Institutional Ethics Committee of Ankara Gulhane Training and Research Hospital (Ethics Committee approval No. 2020/170).

\section{PATIENTS' CONSENT:}

Because this study was retrospective, the patients' consents were waived.

\section{CONFLICT OF INTEREST:}

The authors declared no conflict of interest.

\section{AUTHORS' CONTRIBUTION:}

MBA, IE, RA, GSY, BY, NK: Conception of the work, analysis or interpretation of data for the work, and drafting the work.

\section{REFERENCES}

1. Rajwanshi A, Srinivas R, Upasana G. Malignant small round cell tumors. J Cytol 2009; 26(1):1-10.

2. Stiller CA, Bielack SS, Jundt G, Steliarova-Foucher E. Bone tumours in European children and adolescents, 1978-1997. Report from the automated childhood cancer information system project. Eur J Cancer 2006; 42(13):2124-35. doi: 10.1016/j.ejca.2006.05.015.

3. Longhi A, Errani C, De Paolis M, Mercur M, Bacci G. Primary bone osteosarcoma in the pediatric age: State of the art. Cancer Treat Rev 2006; 32(6):423-36. doi: 10.1016/j.ctrv.2006.05.005.

4. Stevens M, Frobisher C, Hawkins M, Mercuri M, Bacci G. The british childhood cancer survivor study: Objectives, methods, population structure, response rates and initial descriptive information. Pediatr Blood Cancer 2008; 50(5):1018-25. doi: 10.1002/pbc.21335.

5. Obata H, Ueda T, Kawai A, Ishii T, Ozaki T, Abe S, et al. Clinical outcome of patients with Ewing sarcoma family of tumors of bone in Japan: The Japanese musculoskeletal oncology group cooperative study. Cancer 2007; 109(4):767-75. doi: 10.1002/cncr.22481.

6. Lee JW, Kim H, Kang HJ, Kim HS, Park SH, Kim IO, et al. Clinical characteristics and treatment results of pediatric osteosarcoma: The role of high dose chemotherapy with autologous stem cell transplantation. Cancer Res Treat 2008; 40(4):172. doi: 10.4143/crt.2008.40.4.172.
7. Pham T, Robinson K, Vleeshouwer-Neumann T, Annis JE, Chen EY. Characterisation of GRK5 as a novel regulator of rhabdomyosarcoma tumor cell growth and self-renewal. Oncotarget 2020; 11(16):1448-61. doi: 10.18632/oncotarget.27562.

8. Amer KM, Thomson JE, Congiusta D, Dobitsch A, Chaudhry $A$, Li M, et al. Epidemiology, Incidence, and survival of rhabdomyosarcoma subtypes: SEER and ICES database analysis. J Orthop Res 2019; 37(10):2226-30. doi: 10.1002/jor.24387.

9. Stiff PJ, Agovi MA, Antman KH, Blaise D, Camitta BM, Cairo MS, et al. High-Dose Chemotherapy with blood or bone marrow transplants for rhabdomyosarcoma. Biol Blood Marrow Transplant 2010; 16(4):525-32. doi: 10.1016/j. bbmt.2009.11.020.

10. Smoll NR, Drummond KJ. The incidence of medulloblastomas and primitive neurectodermal tumours in adults and children. J Clin Neurosci 2012; 19(11):1541-1544. doi: 10.1016/j.jocn.2012.04.009.

11. Majd N, Penas-Prado M. Updates on management of adult medulloblastoma. Curr Treat Options Oncol 2019; 20(8):64. doi:10.1007/s11864-019-0663-0. doi: 10.1007/s11864019-0663-0.

12. Choi YB, Yi ES, Lee JW, Yoo KH, Sung KW, Koo HH, et al. High-dose chemotherapy and autologous stem cell transplantation in children with high-risk or recurrent bone and soft tissue sarcomas. J Korean Med Sci 2016; 31(7):1055-62. doi: 10.3346/jkms.2016.31.7.1055.

13. Van Winkle $P$, Angiolillo A, Krailo M, Cheung YK, Anderson B, Davenport $V$, et al. Ifosfamide, carboplatin, and etoposide (ICE) reinduction chemotherapy in a large cohort of children and adolescents with recurrent/refractory sarcoma: The children's cancer group (CCG) experience. Pediatr Blood Cancer 2005; 44(4):338-47. doi: 10.1002/pbc.20227.

14. López-Aguilar E, Sepúlveda-Vildósola AC, Rivera-Márquez $H$, Cerecedo-Díaz F, Valdés-Sánchez M, Delgado-Huerta S, et al. Preirradiation ifosfamide, carboplatin and etoposide (ICE) for the treatment of high-grade astrocytomas in children. Child's Nerv Syst 2003; 19(12):818-23. doi:10.1007/ s00381-003-0822-1

15. McTiernan A, Driver D, Michelagnoli MP, Kilby AM, Whelan JS. High dose chemotherapy with bone marrow or peripheral stem cell rescue is an effective treatment option for patients with relapsed or progressive Ewing's sarcoma family of tumours. Ann Oncol 2006; 17(8):1301-05. doi: 10.1093/annonc/mdl108

16. Bacci G, Ferrari S, Longhi A, Donati D, De Paolis M, Forni C, et al. Therapy and survival after recurrence of Ewing's tumors: The Rizzoli experience in 195 patients treated with adjuvant and neoadjuvant chemotherapy from 1979 to 1997. Ann Oncol 2003; 14(11):1654-9. doi: 10.1093/annonc/mdg457.

17. Zia MI, Forsyth P, Chaudhry A, Russell J, Stewart DA. Possible beneqfits of high-dose chemotherapy and autologous stem cell transplantation for adutls with recurrent medulloblastoma. Bone Marrow Transplant 2002; 30(9): 565-9. doi: 10.1038/sj.bmt.1703725.

18. Matsubara $\mathrm{H}$, Makimoto $\mathrm{A}$, Higa $\mathrm{T}$, Kawamoto $\mathrm{H}$, Takayama J, Ohira $\mathrm{M}$, et al. Possible benefits of high-dose chemotherapy as intensive consolidation in patients with high-risk 
rhabdomyosarcoma who achieve complete remission with conventional chemotherapy. Pediatr Hematol Oncol 2003; 20(3):201-10.

19. Arpaci F, Ataergin S, Ozet A, Erler K, Basbozkurt M, Ozcan A, et al. The feasibility of neoadjuvant high-dose chemotherapy and autologous peripheral blood stem cell transplantation in patients with nonmetastatic high grade localised osteosarcoma: results of a phase II study. Cancer 2005; 104(5):1058-65. doi: 10.1002/cncr.21279. 